Revista Destaques Acadêmicos, Lajeado, v. 8, n. 4, 2016. ISSN 2176-3070

DOI: http://dx.doi.org/10.22410/issn.2176-3070.v8i4a2016.1226

www.univates.br/revistas

\title{
DETERMINAÇÃO DE ÁCIDO CÍTRICO E pH EM DIFERENTES CULTIVARES DE LIMÃO E MARCAS DE SUCOS ARTIFICIAIS DE LIMÃO EM PÓ
}

\author{
Luana Gabriela Marmitt ${ }^{1}$, Jonas Betti ${ }^{2}$, Eniz Conceição Oliveira ${ }^{3}$
}

\begin{abstract}
Resumo: A citricultura possui um importante papel socioeconômico e, ainda, os citros são de grande importância na alimentação humana. Dentre eles, podem ser citados os limões que são cultivados desde a antiguidade, principalmente por possuírem propriedades medicinais e valor nutritivo. Com o aumento da industrialização, a busca por praticidade e facilidade na alimentação proporcionou o crescimento no consumo de produtos como sucos artificiais, que possuem poucos nutrientes e diversos aditivos, contribuindo para o desenvolvimento de problemas como erosão dental causada pelo baixo $\mathrm{pH}$ e alergias. Estudos recentes demonstram que o consumo de bebidas cítricas, sendo elas naturais ou artificiais, ocasiona uma queda expressiva no $\mathrm{pH}$ salivar, que se encontra em contato com o esmalte dentário, o qual possui certo grau de tolerância à acidez, levando o consumidor das mesmas a ter problemas como erosão dental e futuramente possíveis cáries. Este trabalho teve como objetivo avaliar o $\mathrm{pH}$ e acidez de três cultivares de limão e três marcas de sucos artificiais em pó de limão. As análises de $\mathrm{pH}$ foram realizadas com $\mathrm{pHmetro}$ digital e as análises de acidez foram realizadas pela técnica de titulometria com $\mathrm{NaOH} 0,1 \mathrm{M}$. Nos sucos artificiais o $\mathrm{pH}$ variou de 2,66 a 2,95 e nos limões variou de 2,69 a 3,03. Já a acidez para os sucos artificiais ficou entre 13,87\% e $26,32 \%$ e para os limões $2,70 \%$ a $6,64 \%$. Portanto, conclui-se que todas as amostras, independentemente de sua origem, podem contribuir para o desenvolvimento da erosão dental, principalmente se houver contato de longa duração.
\end{abstract}

Palavras-chave: Lima ácida. Limão. Acidez. PH.

\section{INTRODUÇÃO}

As plantas cítricas fazem parte do gênero Citrus, da família Rutaceae e da subfamília Aurantioidae (WEILER, 2006). As frutas cítricas que apresentam

1 Graduanda do curso de Química Industrial da Univates, Lajeado/RS.

2 Graduando do curso de Química Industrial da Univates, Lajeado/RS.

3 Doutora em química, Professora da Univates, Lajeado/RS. 
maior teor de acidez são geralmente denominadas como limões, que inclui tanto os limões verdadeiros, como o limão Siciliano [Citrus limon (L)] e também as limas ácidas, como as cultivares Tahiti [Citrus latifolia (Yu. Tanaka) Tanaka] e Galego [Citrus aurantifolia (Christm.) Swingle]. Ainda, podem ser encontrados limões híbridos, como é o caso do limão cravo (Citrus limonia Osbeck), que consiste em um híbrido natural formado a partir da tangerineira (C. reticulata sensu Swingle) e o limoeiro verdadeiro [C. limon (L.) Burm. f.] (WREGE et al., 2006; REBEQUI et al., 2009).

O limão Siciliano apresenta frutos ovalados, grandes com casca grossa e amarela. É bastante aromático e possui acidez moderada, o que o faz ter grande apreciação na cozinha, A lima ácida Tahiti tem frutos levemente ovalados, casca verde não apresenta sementes, sendo também utilizada na culinária. $O$ limão cravo possui boa adaptação em solos arenosos e ligeiramente ácidos, sendo resistente à seca e qualificado como porta-enxerto (JUNIOR et al., $2005 \mathrm{e}$ REBEQUI et al., 2009).

Devido às propriedades medicinais e também pelo seu valor nutritivo, limeiras ácidas e limoeiros verdadeiros são cultivados desde a antiguidade (WREGE et al, 2006). Os citros têm sua origem principalmente nas regiões subtropicais e tropicais do sul e sudeste da Ásia. Na época das Cruzadas foram levados à Europa e chegaram ao Brasil através dos Portugueses no século XVI. Os frutos são ricos em vitaminas, como a vitamina $C$, A, vitaminas do complexo B e sais minerais, como cálcio, potássio, sódio, ferro e fósforo (JUNIOR et al, 2005).

As frutas cítricas possuem um importante papel na alimentação humana, especialmente na forma de suco e fruta fresca. Tanto os frutos de mesma espécie como os frutos de mesa e as cultivares próprias para sucos, são adquiridas pelos consumidores brasileiros, sendo que a disponibilidade desta última variedade é superior quando comparada às cultivares de mesa. Isso ocorre devido à grande influência que a indústria de suco exerce no país (REBEQUI et al, 2009).

A produção de citros pode ser encontrada em todos os continentes, sendo o principal cultivo frutícola mundial (WEILER, 2006). A Itália, Espanha e Estados Unidos tem destaque na produção de limões verdadeiros, já o México, Peru e Brasil, tem destaque na produção de limas ácidas (HENRIQUE e CEREDA, 2007). No Brasil, São Paulo, com $80 \%$ da produção nacional, lidera a produção de limas ácidas e limões, sendo seguido por Rio de Janeiro, Bahia, Rio Grande do Sul, Sergipe, Espírito Santos e Minas Gerais (WREGE et al., 2006).

A citricultura brasileira tem destaque por possuir um valor expressivo de produção e gerar um considerável número de empregos diretos e indiretos, que, em 2006 somavam 400 mil colocações de trabalho (SOARES FILHO et al, 2008). No Rio Grande do Sul, a citricultura é uma prática de pequenas propriedades rurais, portanto, é uma atividade de grande importância socioeconômica, incluindo a produção de limões (WEILER, 2006). 
$\mathrm{O}$ ácido cítrico, com nome oficial ácido 2-hidroxi-1,2,3propanotricarboxílico, possui fórmula molecular $\mathrm{C}_{6} \mathrm{H}_{8} \mathrm{O}_{7}$ e foi descoberto pelo alquimista islâmico Abu Musa Jabir ibn Hayyan, no oitavo século depois de Cristo. Em 1784, foi isolado e cristalizado pela primeira vez a partir do suco de limão pelo químico sueco Carl Wilhelm Scheele. Grimaux e Adam, em 1880, foram os primeiros a realizar a síntese do ácido. Dentre os ácidos utilizados em bebidas, comidas, na área farmacêutica, entre outros exemplos, o cítrico possui um importante papel, possuindo uma produção e comercialização de milhões de toneladas que cresce anualmente. Ele está bastante presente em frutas e vegetais, especialmente nas frutas cítricas, sendo responsável pelo sabor azedo (APELBLAT, 2014; VANDENBERGHE et al., 1999).

A industrialização mudou o estilo de vida e os hábitos alimentares da sociedade, o que provocou maior busca por alimentos industrializados, sendo eles mais calóricos e pouco saudáveis. Os avanços tecnológicos na indústria de alimentos modificaram as práticas alimentares, ocasionando a procura pela praticidade e facilidade na alimentação (REINALDO et al., 2015). Sucos artificiais são exemplos de produtos que estão disponíveis no mercado e que fazem parte da rotina dos consumidores, principalmente pelo seu fácil preparo, grande rendimento e baixo custo. No entanto, tais sucos possuem diversos componentes químicos, apresentando potencial cariogênico, aumentam o risco para o desenvolvimento da erosão dental e, ainda, são propícios a reações alérgicas. Além disso, esses produtos possuem poucos nutrientes, são ultraprocessados e ricos em aditivos (SOARES, BONVINI e FARIAS, 2014).

A erosão dental consiste na perda do tecido mineral dentário causada pela ação de ácidos ou substâncias quelantes sem a atuação de bactérias e pode ser causada por diversos fatores, incluindo ingestão de ácidos que estão presentes em algumas bebidas e alimentos. Como o $\mathrm{pH}$ crítico do esmalte dentário é aproximadamente 5,5, substâncias com pH menor são capazes de causar a erosão dentária, principalmente se o ataque tiver longa duração e ocorrer diversas vezes. Os sucos artificiais possuem na sua formulação diversos ácidos e componentes que podem ter relação com o desenvolvimento da erosão dental, lesões e também reações alérgicas (SOARES, BONVINI e FARIAS, 2014; CORSO, HUGO e PADILHA, 2002).

Diante do exposto e considerando a importância da citricultura e a crescente procura por produtos industrializados, este trabalho teve como objetivo avaliar a acidez (ácido cítrico) e pH do limão Siciliano, limão Cravo, da lima ácida Tahiti e de sucos artificiais de limão disponíveis no mercado.

\section{MATERIAL E MÉTODOS}

Neste experimento, utilizou-se o limão Siciliano, o limão Cravo, a lima ácida Tahiti e três marcas distintas de sucos artificiais de limão em pó, denominadas S1, S2 e S3. As amostras de sucos artificiais foram adquiridas 
no município de Encantado no mês de outubro de 2016 em estabelecimentos comerciais e as amostras das frutas foram coletadas diretamente de propriedades rurais da mesma.

As análises de $\mathrm{pH}$ foram realizadas com $\mathrm{pHmetro}$ digital da marca Digimed, modelo DM-22. O teor de acidez foi baseado na metodologia descrita por Adolfo Lutz (INSTITUTO ADOLFO LUTZ, 2008), na qual a determinação é realizada através da titulação com $\mathrm{NaOH} 0,1 \mathrm{M}$ previamente padronizado.

Para as análises de acidez nas frutas, o suco foi coado e $20 \mathrm{~mL}$ do mesmo foram transferidos para um balão de $200 \mathrm{~mL}$. Após a diluição, $20 \mathrm{~mL}$ da solução foram titulados com $\mathrm{NaOH}$. Nos sucos artificiais, a preparação foi feita conforme estabelecido pelo fabricante e $20 \mathrm{~mL}$ foram retirados e titulados. Para todas as diluições realizadas foi utilizada água deionizada a temperatura ambiente e as titulações foram feitas em triplicata.

As leituras de $\mathrm{pH}$ foram realizadas no suco puro e no diluído das frutas e no suco artificial preparado conforme descrito na embalagem.

\section{RESULTADOS E DISCUSSÃO}

Os ingredientes de acordo com o fabricante dos sucos artificiais em pó utilizados nas análises estão descritos no Quadro 1.

Quadro 1 - Composição dos sucos artificiais em pó

\begin{tabular}{|c|l|}
\hline Amostra & \multicolumn{1}{c|}{ Ingredientes } \\
\hline S1 & $\begin{array}{l}\text { Açúcar, maltodextrina, polpa de limão desidratada, vitaminas C, D, E, } \\
\text { mineral sulfato de zinco, acidulante ácido cítrico, antiumectante fosfa- } \\
\text { to tricálcio, edulcorantes: aspartame, ciclamato de sódio, acesulfame } \\
\text { de potássio e sacarina de sódio, regulador de acidez citrato trissódico, } \\
\text { espessantes: gomas guar e xantana, aromatizante, corantes: dióxido de } \\
\text { titânio, tartrazina e azul brilhante FCF e espumante extrato de quilaia. }\end{array}$ \\
\hline S2 & $\begin{array}{l}\text { Açúcar, suco de limão desidratado, vitamina C, acidulante ácido cítri- } \\
\text { co, aroma idêntico ao natural de limão, regulador de acidez citrato de } \\
\text { sódio, edulcorantes artificiais: aspartame (24 mg/100 mL) e acesulfame } \\
\text { de potássio (3,6 mg/100 mL), espessante carboximetilcelulose sódica, } \\
\text { antiumectante fosfato tricálcico, corante inorgânico dióxido de titânio, } \\
\text { corante artificial amarelo tartrazina. }\end{array}$ \\
\hline S3 & $\begin{array}{l}\text { Açúcar, suco de limão desidratado, vitamina C (ácido ascórbico), acidu- } \\
\text { lante ácido cítrico, edulcorantes artificiais aspartame (10 mg/100 mL), } \\
\text { ciclamato de sódio (8 mg/100 mL), acesulfame -k (3,6 mg/100 mL) e } \\
\text { sacarina sódica (1 mg/100 mL), corante inorgânico dióxido de titânio, } \\
\text { aromatizante (aroma idêntico ao natural de limão), antiumectante fos- } \\
\text { fato tricálcio, regulador de acidez citrato de sódio, espessante carboxi- } \\
\text { metilcelulose sódica e corantes artificiais tartrazina e azul brilhante FCF. }\end{array}$ \\
\hline
\end{tabular}

Fonte: Rótulos dos sucos. 
Todos os sucos apresentaram $\mathrm{pH}$ inferior a 5,5, variando entre 2,38 e 3,03 para as frutas e 2,66 e 2,95 para os sucos artificiais, conforme a Tabela 1.

Tabela 1 - Valores de $\mathrm{pH}$ obtidos nas amostras

\begin{tabular}{ccc}
\hline Amostra & $\mathbf{p H}$ & $\mathbf{p H}$ (suco puro) \\
\hline Limão Siciliano & 3,03 & 2,83 \\
Lima ácida Tahiti & 2,69 & 2,38 \\
Limão Cravo & 2,71 & 2,42 \\
S1 & 2,95 & - \\
S2 & 2,92 & - \\
S3 & 2,66 & - \\
\hline
\end{tabular}

Vitaminas e ácidos estão naturalmente presentes no limão, porém ácidos e outros compostos podem ser acrescentados na composição de sucos industrializados exercendo funções como antioxidantes e reguladores de $\mathrm{pH}$. Tais componentes podem vir a causar erosão dental e reações alérgicas nos consumidores (SOARES, BONVINI e FARIAS, 2014).

Os valores de $\mathrm{pH}$ encontrados nos sucos artificiais são semelhantes aos obtidos no estudo de Soares, Bonvini e Farias (2014), no qual as diferentes marcas analisadas apresentaram valores que variaram entre 2,81 e 3,12.

Por serem produtos industrializados, apresentando uma composição com diversos ingredientes artificiais, e, ainda, contendo um alto índice de ácido cítrico, eles apresentam um grande potencial erosivo. Sabe-se, por meio de estudos, que o $\mathrm{pH}$ ao qual o esmalte dentário é capaz de suportar é de aproximadamente 5,5. Então, a partir do estudo realizado, nota-se que o suco de limão, sendo ele natural ou artificial, pode vir a causar a erosão dental, principalmente se o contato com o mesmo for duradouro (MEURMAN, TEN CATE, 1996). Tal fato ocorre, pois provocam a baixa do $\mathrm{pH}$ salivar desencadeando a dissolução do esmalte dentário (FEATHERTONE; LUSSI, 2006).

Quanto ao ácido cítrico, as quantidades variaram entre 2,70 a 6,64\% para os sucos das frutas e 13,87 a $26,32 \%$ para os sucos artificiais em pó, conforme apresentado na Tabela 2. 
Tabela 2: Porcentagem média de ácido cítrico encontrada nas amostras e desvio do padrão

\begin{tabular}{cc}
\hline Amostra & Média de ácido cítrico (\%) \\
\hline Limão Siciliano & $2,70 \pm 0,00$ \\
Lima ácida Tahiti & $6,64 \pm 0,05$ \\
Limão Cravo & $5,28 \pm 0,04$ \\
S1 & $26,32 \pm 0,13$ \\
S2 & $19,75 \pm 0,11$ \\
S3 & $13,87 \pm 0,12$ \\
\hline
\end{tabular}

De acordo com a Tabela 2, pode-se perceber que a presença de ácido cítrico é muito maior em produtos artificiais do que naturais. Sabendo-se que os sucos artificiais foram preparados com os ingredientes descritos na embalagem, nota-se que outros componentes podem ter afetado na quantificação do ácido cítrico presente na amostra. É possível perceber que a amostra S1 apresenta a maior quantidade de ácido cítrico. Esta diferença ocorre devido ao fato desta amostra ser produzida a partir da polpa do limão desidratado, enquanto que as demais amostras artificiais são preparadas com suco de limão desidratado.

Comparando-se os resultados da Tabela $1 \mathrm{com}$ a Tabela 2, percebe-se que mesmo com o grande aumento da concentração de ácido cítrico presente nas amostras industrializadas, os valores de $\mathrm{pH}$ apresentaram-se aproximados. Em alguns casos até se mostra mais alto em relação às amostras naturais. Os valores aproximados das amostras artificiais são obtidos pois na composição das mesmas são adicionados citrato de sódio, que atua como regulador de $\mathrm{pH}$, tornando-as o mais próximo possível da sua forma natural.

Dentre todas as amostras analisadas, o limão Siciliano apresentou maior valor de $\mathrm{pH}$ e menor valor de ácido cítrico, o que está de acordo com (JUNIOR et al., 2005), que informa que esta fruta possui uma acidez mais agradável.

A lima ácida Tahiti resultou no menor $\mathrm{pH}$ entre as frutas e na maior quantidade de ácido cítrico. O valor de ácido cítrico encontrado, 6,64\%, se difere do valor obtido no estudo de Pedrão et al (1999), que é de 5,56\% do ácido nesta mesma cultivar. Esta variação ocorre pois diversos fatores podem influenciar na composição química da fruta, como o clima, tipo de solo, tratos culturais, entre outros (MENDONÇA et al., 2006).

Já entre os sucos artificiais, a amostra S3 apresentou menor $\mathrm{pH}$ e menor quantidade de ácido cítrico, enquanto a amostra S1 obteve maior $\mathrm{pH}$ e maior porcentagem de ácido cítrico. 


\section{CONCLUSÃO}

Dentre os vários resultados obtidos a partir do processo titulométrico, determinou-se que independente de sua origem, os valores de $\mathrm{pH}$ encontrados nas amostras apresentaram-se próximos. Para o índice de ácido cítrico nas mesmas, foi possível identificar valores muito maiores nas amostras de sucos em pó pois estas apresentam componentes químicos artificiais em sua composição. Conclui-se também que o consumo excessivo do suco de limão, seja ele natural ou artificial, pode vir a causar o desgaste dos tecidos dentários duros. Além disso, sucos artificiais podem acarretar problemas como cáries e alergias.

\section{REFERÊNCIAS}

APELBLAT, Alexander. Citric Acid. Springer International Publishing Switzerland, 2014.

CORSO, Ana Carolina; HUGO, Fernando Neves; PADILHA, Dalva Maria Pereira. pH e tirabilidade ácida de sucos artificiais de limão. Revista da Faculdade de Odontologia de Porto Alegre, v. 43, n. 1, p. 30-33, jul. 2002.

HENRIQUE, Celina Maria.; CEREDA, Marney Pascoli. Uso de ethephon e fécula de mandioca na conservação pós-colheita de limão siciliano. Revista de Biologia e Ciências da Terra, v. 7, n. 1, p. 99-106, Universidade Estadual da Paraíba, 2007.

INSTITUTO ADOLFO LUTZ. Métodos físico-químicos para análise de alimentos. 4 ed, p. 168. São Paulo, 2008.

JUNIOR, Dirceu de Mattos et al. CITROS: principais informações e recomendações de cultivo. Instituto agronômico de Campinas, 2005.

MENDONÇA, Luciana Maria Vieira Lopes et al. Caracterização da composição química e do rendimento dos resíduos industriais do limão Tahiti (Citrus latifólia Tanaka). Ciência e Tecnologia de Alimentos, p. 870-874, Campinas, 2006.

MEURMAN, Jukka H.; TEN CATE, J. M. Pathogenesis and modifying factors of dental erosion. European Journal of oral Sciences, 1996.

PEDRÃO, Mayka R. et al. Estabilidade físico-química e sensorial do suco de limão Tahiti natural e adoçado, congelado. Ciência e Tecnologia de Alimentos, 1999.

REBEQUI, Alex Matheus et al. Produção de mudas de limão cravo em substrato com biofertilizante bovino irrigado com águas salinas. Revista de Ciências Agrárias, 2009.

REINALDO Figueirêdo et al. Mudanças de hábitos alimentares em comunidades rurais do semiárido da região nordeste do Brasil. Interciência, vol. 40, n. 5, p. 330-336, Venezuela, 2015. 
SOARES, Ana Keila; BONVINI, Brenda; FARIAS, Maria Mercês A. Gouveia. Avaliação do potencial erosivo e cariogênico de sucos artificiais em pó. Revista de Odontologia da Universidade Cidade de São Paulo v. 26, n. 3, p. 197-203, São Paulo, 2014 .

SOARES FILHO, Walter dos Santos et al. Potencial de obtenção de novos portaenxertos em cruzamentos envolvendo limoeiro 'cravo', laranjeira 'azeda', tangerineira 'sunki' e híbridos de Poncirus trifoliata. Revista Brasileira de Fruticultura, v. 30, n. 1, p. 223-228, São Paulo, 2008.

VANDENBERGHE, Luciana P. S. et al. Microbial Production of Citric Acid. Braz. arch. biol. technol., v. 42, n. 3, p. 263-276, Curitiba, 1999

WEILER, Roberto Luis. Caracterização morfológica, citogenética e molecular de uma população de tangerineiras híbridas de 'clementina fina' (Citrus clementina Hort. Ex Tan) e 'Montenegrina' (Citrus deliciosa Tem.). Dissertação de mestrado, UFRGS, 2006

WREGE, Marcos Silveira et al. Zoneamento agroclimático para a produção de limas ácidas e de limões no Rio Grande do Sul. Pelotas: Embrapa Clima Temperado, 2006. 